\title{
Fire Engineer Suffers Sudden Cardiac Death at Shift Change - California
}

\section{Executive Summary}

On January 20, 2014, a 49-year-old male career Fire Engineer (FE) was scheduled to work his regular 24-hour shift. This would have been his third consecutive 24-hour shift as he volunteered to work a 24hour overtime shift the day before. During the first 48 hours, the FE responded to seven medical calls, none of which required heavy physical exertion; he did not complain of any symptoms. When the FE did not attend the third shift change meeting ( 0800 hours), crew members found him unresponsive in his bunk. Advanced life support (ALS) including cardiac defibrillation was performed and the FE was transported to the hospital's emergency department (ED). Despite cardiopulmonary resuscitation (CPR) and ALS at the scene, in the ambulance, and in the hospital's ED, the FE died. The death certificate and the autopsy listed "hypertensive cardiovascular disease with marked cardiomegaly" as the cause of death with "mitral valve prolapse, clinical history of hypertension, and left bundle branch block" as significant other conditions. Given the FE's undiagnosed underlying coronary heart disease (CHD), NIOSH investigators concluded that an arrhythmia probably triggered his sudden cardiac death.

\section{Key Recommendations}

- Provide mandatory annual medical evaluations to all fire fighters consistent with the current edition of National Fire Protection Association (NFPA) 1582, Standard on Comprehensive Occupational Medical Program for Fire Departments

- Perform symptom-limiting exercise stress tests for fire fighters at risk for CHD and sudden cardiac events

- Phase in a mandatory comprehensive wellness and fitness program for fire fighters.

- Perform an annual physical performance (physical ability) evaluation for all members.

The following recommendations address general safety and health issues:

- Limit the number of consecutive shifts a fire fighter can work

- Discontinue routine screening chest x-rays for members unless clinically indicated. 


\section{Fire Engineer Suffers Sudden Cardiac Death at Shift Change - California}

The National Institute for Occupational Safety and Health (NIOSH), an institute within the Centers for Disease Control and Prevention (CDC), is the federal agency responsible for conducting research and making recommendations for the prevention of work-related injury and illness. In 1998, Congress appropriated funds to NIOSH to conduct a fire fighter initiative that resulted in the NIOSH "Fire Fighter Fatality Investigation and Prevention Program" which examines line-of-duty-deaths or on duty deaths of fire fighters to assist fire departments, fire fighters, the fire service and others to prevent similar fire fighter deaths in the future. The agency does not enforce compliance with State or Federal occupational safety and health standards and does not determine fault or assign blame. Participation of fire departments and individuals in NIOSH investigations is voluntary. Under its program, NIOSH investigators interview persons with knowledge of the incident who agree to be interviewed and review available records to develop a description of the conditions and circumstances leading to the death(s). Interviewees are not asked to sign sworn statements and interviews are not recorded. The agency's reports do not name the victim, the fire department or those interviewed. The NIOSH report's summary of the conditions and circumstances surrounding the fatality is intended to provide context to the agency's recommendations and is not intended to be definitive for purposes of determining any claim or benefit.

For further information, visit the program website at www.cdc.gov/niosh/fire or call toll free 1-800-CDC-INFO (1-800-232-4636). 


\section{Death in the line of duty... N/OSH}

A summary of a NIOSH fire fighter fatality investigation

\section{Introduction}

On January 20, 2014, a 49-year-old male career FE died shortly after shift change. NIOSH was notified of this fatality on January 21, 2014, by the U.S. Fire Administration. NIOSH contacted the affected Fire Department (FD) on January 21, 2014, to gather additional information and on January 6, 2015, to initiate the investigation. On January 13, 2015, a safety and occupational health specialist from the NIOSH Fire Fighter Fatality Investigation Team conducted an on-site investigation of the incident.

During the investigation, NIOSH personnel interviewed the following people:

- FD Division III Chief

- FD Operations \& Safety Battalion Chief

- FD Emergency Medical Services Battalion Chief

- Risk Manager

- Risk Management Safety Officer

- IAFF Local Vice President

- Wellness Fitness (WEFIT) Coordinator

- Crew members

- FE's spouse

NIOSH personnel reviewed the following documents:

- FD training records

- FD annual report for 2013

- FD incident report

- FD medical records

- Emergency medical service (ambulance) incident report

- Hospital ED records

- Death certificate

- Autopsy report 


\section{Investigation}

On January 18, 2014, the FE worked his scheduled 24-hour shift. During the shift, he responded to two calls: a medical call in which the FE provided basic medical care, and a second call which was cancelled en route. On January 19, he worked a voluntary 24-hour overtime shift. During this shift the FE responded to five medical calls: four calls to provide ALS care and one call cancelled on-scene. None of these responses required heavy physical exertion and during the responses the FE did not report or appear to have any medical problems.

On January 20, 2014, at about 0630 hours, the FE took a shower prior to his regularly scheduled 24-hour shift which began at 0800 hours. Crew members noted the FE did not attend the shift change meeting. After the meeting at approximately 0930 hours, crew members found the FE on his bunk, unresponsive, not breathing, and with no pulse.

Dispatch was notified as a cardiac monitor was applied (0938 hours). CPR and ALS were begun including two defibrillation attempts and endotracheal intubation. Proper tube placement was verified by positive lung sounds, chest rise, and capnography [Neumar et al. 2010]. His heart rhythm reverted to asystole (no heart beat). An intravenous line was placed and cardiac resuscitation medications were administered as the FE was loaded onto a stretcher and placed into the ambulance. Medic 45 departed the scene en route to the hospital ED at 0949 hours with no change in the FE's clinical condition during transport.

The ambulance arrived at the ED (1000 hours), where ALS continued. After 16 additional minutes of ALS without positive change in the FE's clinical status, the FE was pronounced dead by the attending physician (1016 hours), and resuscitation efforts were discontinued.

\section{Medical Findings}

The death certificate and the autopsy listed "hypertensive cardiovascular disease with marked cardiomegaly" as the cause of death with "mitral valve prolapse, a clinical history of hypertension, and left bundle branch block" as significant conditions. Pertinent findings from the autopsy included cardiomegaly and left ventricular hypertrophy (LVH).

The FE had the following medical conditions:

Hypertension - first diagnosed in 2005 with prescription medication beginning in 2013. Mild concentric LVH, a complication of hypertension was first noted on echocardiogram in 2007, and confirmed at autopsy.

Cardiac arrhythmia - left bundle branch block (LBBB) -first noted on a resting electrocardiogram (EKG) in 2007. In 2007, the consulting cardiologist obtained an 
echocardiogram (see results below) and an adenosine imaging stress test (the results were normal).

Myxomatous mitral valve - (mild prolapse) noted on echocardiogram in 2007, 2009, and on autopsy in 2014.

Borderline obesity - most recent BMI was 30.1 kilograms per meter squared; skinfold thickness in August 2013 calculated a body fat percentage of 28.2\% [CDC 2014; ACE 2015].

Low aerobic capacity - The FE participated in a biannual medical evaluation as part of the FD's WEFIT program. The WEFIT medical evaluation is not structured to medically clear fire fighters for duty, but rather promote fitness and wellness. As part of the WEFIT program, the FE underwent a biannual aerobic capacity test. This test was conducted on a treadmill using the Gerkin protocol with EKG and blood pressure monitoring [Gerkin et al. 1997; Mier and Gibson 2004; Tierney et al. 2010]. The test was last performed in August 2013, 5 months prior to his death. The FE exercised for 4 minutes achieving 6.3 metabolic equivalents (METs) when the test was stopped due to his reaching $85 \%$ of his maximum predicted heart rate. He reported no angina, his blood pressure showed a normal increase with exercise, while the EKG showed LBBB which obscures EKG ischemic changes [Mirvis and Goldberger 2012]. These findings were similar to the aerobic capacity tests in 2007, 2009, and 2011.

\section{Fire Department}

At the time of the NIOSH investigation, the FD consisted of 71 fire stations in 23 cities with 959 career and 280 reserve uniformed personnel. The FD served 1.7 million residents in a geographic area of 575 square miles, including 175,000 acres of wildland. In 2013, the FD responded to 112,333 emergency incidents with 196,298 individual unit responses: 1,919 fire calls, 81,182 emergency medical calls, 1,441 hazardous condition calls, 7,586 service calls, 13,989 good intent calls, 6,012 false alarms, and 178 miscellaneous calls. The FE was usually assigned to Station 45. His engine, Engine 45, responded to 1,400 calls in 2013 while Truck 45 responded to 815 calls and Medic 45 responded to 1,689 calls.

\section{Employment, Training, and Experience}

The FD requires new full-time fire fighter applicants to be 18 years of age ( 21 years to drive fire apparatus); have a valid State driver's license; complete an interest card; pass a written examination; complete an application and provide a resumé; pass a physical agility test (Biddle Test [described below]); and pass an interview. The successful candidate is placed into a group of potential new hires. The new hire is given a preplacement medical evaluation (described below) and sent to the 16-week Fire Fighter Academy to become State-certified as a Fire Fighter I. After successfully completing the Fire Academy, the new hire is placed on a shift working 48 hours on-duty and 96 hours off-duty (0800 hours to 0800 hours). The FE was certified as a Fire Fighter Page 4 
II, Driver/Operator, Fire Officer, Emergency Medical Technician-Intermediate, Fire/Arson Investigator, Fire Instructor, Wildland Faller Class A, Wildland Fire Fighter, Wildland Engine Operator, Wildland Engine Boss, Single Resource, Wildland Fireline Emergency Medical Technician, Wildland Medical Unit Leader, and Wildland Equipment Manager. He also had Associate degrees in Fire Administration and Public Fire Service. He had 24 years of career fire fighting experience at his current FD and about 3 years of volunteer fire fighting experience in another state.

\section{Physical Agility Tests}

Applicants must complete the FD's physical agility test prior to completing a formal application for hire. Applicants are given a preparation guide to train prior to attempting the agility test. The test is a timed evaluation (must be completed within 9 minutes and 34 seconds or less) consisting of the following eleven stations: dry hose deployment, charged hose deployment, halyard raise, roof walk, attic crawl, roof ventilation, victim removal, ladder removal/carry, stair climb with hose pack, attic crawl, and hose hoist. The FD does not have a member physical ability test.

\section{Preplacement and Annual Medical Evaluations/Return to Work Medical Evaluations}

The FD requires preplacement medical evaluations for all applicants. Components of the medical evaluation include the following:

- Complete medical history

- Physical examination (including vital signs, range of motion, reflexes and strength, and hand grip strength); rectal/obstetric exam for those over age 40

- Complete blood count with lipid panel

- Pulmonary function test

- Resting EKG

- Chest x-ray (baseline)

- Urinalysis

- Urine drug screen

- Audiogram

- Vision screen

- Fitness treadmill (aerobic capacity test) for fire fighters over the age of 35

- Immunization and infectious disease screening 
The evaluation is performed by the medical clinic also under contract to conduct the WEFIT medical evaluations (see below). Once this evaluation is complete, the contracted clinic's physician makes a determination regarding the applicant's medical clearance to wear a respirator and medical clearance to perform fire fighting duties. This determination is then forwarded to the FD. The FE joined this FD in 1989. It is unclear if a preplacement medical evaluation was conducted at that time. He was last cleared for unrestricted duty 3 months before his death.

As part of the WEFIT program, the FD offers voluntary medical evaluations for all members every 18 months. Approximately $90 \%$ of the fire fighters participate in this voluntary program. The components of this medical evaluation are the same as for the preplacement evaluation except that: 1) the urine drug screen is not done unless clinically indicated, 2) the chest x-ray is done every 5 years [more frequently for HAZMAT and urban search and rescue teams], and 3) a prostate specific antigen test is done on all male fire fighters beginning at age 40. Fire fighters at high risk for a cardiac event (based on age, number and severity of CHD risk factors) are referred to a cardiologist for a symptom limiting exercise stress test (EST). Once completed, the clinic's physician provides results of the evaluation (including the EST) to the FD member verbally and in writing. The clinic's physician does not, however, release findings of the WEFIT medical evaluation to the FD medical director or the FDcontracted physicians doing "return-to-work" evaluations unless the fire fighter signs a medical release form.

Members injured/ill while on duty and who miss one shift must be evaluated by the FD-contracted occupational medicine physician who forwards a determination for return to duty to the FD. Members who are injured/ill while off duty and miss five shifts or 14 calendar days must also be cleared for return to duty by the FD-contracted occupational medicine physician. The FD has a rehabilitation program for injured members provided through a third party vendor. The program is paid for by the FD, and FFs may attend during their on-duty time. A self-contained breathing apparatus facepiece fit test is conducted annually for all fire fighters.

\section{Wellness/Fitness Programs}

The FD has a voluntary wellness/fitness program, and exercise equipment is available in most fire stations. However, exercise time is not protected time (i.e., the employee is not taken out of service). The FD offers free local gym membership for employees working in fire stations without fitness equipment. Annual physical agility tests are not required for members.

\section{DISCUSSION}

\section{Sudden Cardiac Events}

In the United States, atherosclerotic coronary artery disease (CAD) is the most common risk factor for cardiac arrest and sudden cardiac death [Meyerburg and Castellanos 2008]. Risk factors for its development include age older than 45, male gender, family history of CAD, smoking, high blood pressure, high blood cholesterol, obesity/physical inactivity, and diabetes [NHLBI 2014; AHA 2015]. The FE had three CAD risk factors (age over 45, male gender, and hypertension).

The narrowing of the coronary arteries by atherosclerotic plaques occurs over many years, typically decades [Libby 2013]. Establishing a recent heart attack requires any of the following: elevated cardiac enzymes, coronary artery thrombus, or characteristic EKG changes. In this case, the FE's cardiac enzymes were not tested, no acute coronary artery thrombus was revealed at autopsy, and he did not

Page 5 
have a heart rhythm to conduct an EKG. Given the FE's lack of angina, a cardiac arrhythmia (discussed below), rather than a heart attack, was the likely cause of his sudden cardiac death.

\section{Primary Arrhythmia}

A primary cardiac arrhythmia (e.g., ventricular tachycardia/fibrillation) was likely responsible for the FE's sudden cardiac death. Risk factors for arrhythmias include heart disease, heart attack, dietary supplements, smoking, alcohol, drug abuse, medications, diabetes, and hyperthyroidism [AHA 2014; Mayo Clinic 2015]. The FE had known heart disease (LBBB, mild LVH, and mitral valve prolapse) prior to his death, and all three conditions were confirmed at autopsy. All three conditions increase the risk for a primary arrhythmia [AHA 2014].

\section{Left Ventricular Hypertrophy}

On autopsy and during the FE's stress echocardiogram, the FE was found to have concentric LVH, which increases the risk for sudden cardiac death [Levy et al. 1990]. Hypertrophy of the heart's left ventricle is a relatively common finding among individuals with long-standing hypertension, a heart valve problem, or chronic cardiac ischemia (reduced blood supply to the heart muscle) [Siegel 1997]. The FE's LVH was probably due to a combination of his hypertension and moderate mitral valve prolapse.

\section{Mitral Valve Prolapse}

Mitral valve prolapse occurs when one or both of the mitral valve leaflets prolapse into the left atrium during systole (contraction of the heart muscle). It is the most common heart valve disorder, affecting about 2\%-4\% of the population. Both sexes and all ages can be affected [O'Gara and Braunwald 2008]. The prolapse can be due to problems with the valve leaflets or other parts of the mitral valve apparatus (e.g., annulus; chordae tendineae; papillary muscles; and the supporting walls of the left ventricle, left atrium, and the aorta) [Bonow et al. 2006; Gabbay and Yosefy 2010]. Problems with the valve leaflets are classified as primary mitral valve prolapse (Appendix B).

The basic microscopic feature of primary mitral valve prolapse is marked thickening and redundancy of the middle layer of the valve leaflet (myxomatous proliferation of the spongiosa connective tissue) [Bonow et al. 2006]. The FE's mitral valve prolapse was first identified in 2007. A follow-up was recommended in 5 years (2012) but medical records did not indicate that follow-up visit was performed. Clinical presentations of mitral valve prolapse range from asymptomatic heart murmurs to severe mitral valve regurgitation with symptoms of fatigue, shortness of breath on exertion, and reduced exercise tolerance [O'Gara and Braunwald 2008]. The diagnosis is made by echocardiography, which measures the abrupt posterior movement of one or both of the mitral valve leaflets [Malkowski and Pearson 2000]. The EKG is usually normal in asymptomatic patients, but more severe cases can show signs of LVH. The FE's mitral valve prolapse may have contributed to his low aerobic capacity (6.3 METs) and poor exercise tolerance.

\section{Occupational Medical Standards for Structural Fire Fighters}

To reduce the risk of sudden cardiac arrest or other incapacitating medical conditions among fire fighters, the NFPA developed NFPA 1582, Standard on Comprehensive Occupational Medical Program for Fire Departments [NFPA 2013a]. This voluntary industry standard provides the components of a preplacement and annual medical evaluation and medical fitness for duty criteria. The FE had the following conditions addressed by NFPA 1582: LBBB, mitral valve prolapse, hypertension, and low aerobic capacity. 


\section{Atrioventricular Block}

NFPA 1582 considers LBBB to potentially compromise a member's ability to safely perform as an integral component of a team, where sudden incapacitation of a member can result in mission failure or in risk of injury or death to civilians or other team members [NFPA 2013a]. Members with LBBB should be restricted if heart rate does not increase with exercise, left ventricular function is abnormal, or there are structural cardiac abnormalities. The FE did not meet the latter criterion; he had mitral valve prolapse diagnosed by echocardiography in 2007, 2009, and confirmed at autopsy.

\section{Mitral Valve Prolapse}

NFPA 1582 considers mitral valve prolapse to only interfere with safe performance of critical job tasks if it is associated with arrhythmias or if moderate to severe mitral regurgitation is present. The FE had only mild mitral regurgitation during his stress echocardiogram in May 2009.

\section{Hypertension}

NFPA 1582 suggests that members with stage I hypertension be referred to their primary care physician to ensure that their blood pressure is controlled and to consider periodic screening for asymptomatic end organ damage based on the severity and duration of their hypertension [NFPA 2013a]. The FE had stage I hypertension diagnosed in 2005, but he was not prescribed a blood pressure-lowering medication until 2013. His most recent blood pressure readings were within normal limits.

\section{Aerobic Capacity and Exercise Stress Tests}

The NFPA identifies 12 METs as the necessary level of aerobic capacity for fire fighting activities [NFPA 2013a]. For fire fighters who are not able to achieve 8 METs, "a prescribed aerobic fitness program shall be required, and the authority having jurisdiction shall be advised to consider restrictions from essential job tasks 1, 2, 4, 5, 6, 7, 8, 9, and 13" [NFPA 2013a]. Five months prior to his death the FE had an aerobic capacity test performed by the clinic conducting the WEFIT medical evaluations. As noted previously, the FE exercised for 4 minutes and stopped when he reached $85 \%$ of his maximal heart rate, achieving 6.3 METS. According to NFPA 1582, the FE should have been given restrictions [NFPA 2013a].

\section{County Occupational Health Program's WEFIT Program}

The primary purpose of the WEFIT program is the promotion of health and physical fitness. Current participation in the program is $90 \%$ per year. The FD believes that a more aggressive approach to fitness-for-duty would result in a substantial drop in participation rates, thus be counter-productive to the program's primary goal of promoting health and physical fitness.

\section{Recommendations}

Recommendation \#1: Provide mandatory annual medical evaluations to all fire fighters consistent with the current edition of National Fire Protection Association (NFPA) 1582, Standard on Comprehensive Occupational Medical Program for Fire Departments.

Discussion: The WEFIT seeks to promote health and fitness. We applaud the FD and the union for implementing the WEFIT program. However, the FD is currently conducting the medical evaluations every 18 months, not every year, and approximately $10 \%$ of fire fighters are not participating in this generous program. In addition, by not sharing the WEFIT medical evaluation findings with the FD medical director, the NFPA goal of ensuring that fire fighters are not a risk to themselves or others, is 
not met by the WEFIT program as it currently is designed. We recommend the FD require annual member medical evaluations consistent with NFPA 1582 and the results be shared with the appropriate FD medical personnel.

\section{Recommendation \#2: Perform symptom-limiting exercise stress tests for fire fighters at risk for coronary heart disease and sudden cardiac events.}

Discussion: The FD currently provides biannual voluntary aerobic capacity tests with EKG monitoring as part of the WEFIT program. Fire fighters at high risk for a cardiac event are referred to a cardiologist for a symptom-limiting exercise stress test. "High risk" is determined by the findings/symptoms from the WEFIT aerobic capacity fitness test.

NFPA 1582, a voluntary industry standard, recommends an EST be performed "as clinically indicated by history or symptoms" and refers the reader to Appendix A [NFPA 2013a]. Items in Appendix A are not standard requirements, but are provided for "informational purposes only." Appendix A recommends using submaximal (85\% of predicted heart rate) EST as a screening tool to evaluate a fire fighter's aerobic capacity. Maximal (i.e., symptom-limiting) EST with imaging should be used for fire fighters with the following conditions:

- abnormal screening submaximal tests

- cardiac symptoms

- known CHD

- one or more risk factors for CHD (in men older than 45 and women older than 55)

- Framingham Risk Score > 10\%

Risk factors are defined as hypercholesterolemia (total cholesterol greater than 240 milligrams per deciliter), hypertension (diastolic blood pressure greater than $90 \mathrm{~mm}$ of mercury), smoking, diabetes mellitus, or family history of premature CHD (heart attack or sudden cardiac death in a first-degree relative less than 60 years old).

The ACC/AHA has also published exercise testing guidelines [Gibbons et al. 2002]. The ACC/AHA guideline states that the evidence to conduct stress tests in asymptomatic individuals is "less well established" (Class IIb) for the following groups:

- persons with multiple risk factors (defined similarly to those listed by the NFPA)

- asymptomatic men older than 45 years and women older than 55 years:

o who are sedentary and plan to start vigorous exercise

o who are involved in occupations in which impairment might jeopardize public safety (e.g., fire fighters)

O who are at high risk for coronary artery disease due to other diseases (e.g., peripheral vascular disease and chronic renal failure)

Given the FE's age, hypertension, and work as a public safety official, both NFPA 1582 and the ACC/AHA guidelines suggest a symptom-limiting EST would have been appropriate. In addition, a nuclear imaging EST should have been considered given the presence of LBBB which can mask ischemic changes [Baltazar 2009]. 


\section{Recommendation \#3: Phase in a mandatory comprehensive wellness and fitness program for fire fighters.}

Discussion: Guidance for fire department wellness/fitness programs to reduce risk factors for cardiovascular disease and improve cardiovascular capacity is found in NFPA 1583, Standard on Health-Related Fitness Programs for Fire Fighters, the IAFF/IAFC Fire Service Joint Labor Management Wellness/Fitness Initiative, and in Firefighter Fitness: A Health and Wellness Guide [IAFF, IAFC 2008; NFPA 2008; Schneider 2010]. Worksite health promotion programs have been shown to be cost effective by increasing productivity, reducing absenteeism, and reducing the number of work-related injuries and lost work days [Stein et al. 2000; Aldana 2001]. Fire service health promotion programs have been shown to reduce CAD risk factors and improve fitness levels, with mandatory programs showing the most benefit [Dempsey et al. 2002; Womack et al. 2005; Blevins et al. 2006]. A study conducted by the Oregon Health and Science University reported a savings of more than $\$ 1$ million for each of four large fire departments implementing the IAFF/IAFC wellness/fitness program compared to four large fire departments not implementing a program. These savings were primarily due to a reduction of occupational injury/illness claims with additional savings expected from reduced future nonoccupational healthcare costs [Kuehl et al. 2013].

The FD has an outstanding voluntary wellness/fitness program. However, NIOSH recommends a formal, structured wellness/fitness program to ensure ALL members receive the benefits of a health promotion program. In addition, during exercise time, employees should be taken out of service to ensure uninterrupted member participation.

\section{Recommendation \#4: Perform an annual physical performance (physical ability) evaluation.}

Discussion: NFPA 1500, Standard on Fire Department Occupational Safety and Health Program, requires the FD to develop physical performance requirements for candidates and members who engage in emergency operations [NFPA 2013b]. Members who engage in emergency operations must be annually qualified (physical ability test) as meeting these physical performance standards for structural fire fighters [NFPA 2013b]. While the biannual aerobic capacity test determines the member's aerobic capacity, this is just one requirement for a structural fire fighter. Once developed by the FD, this evaluation could be performed as part of the FD annual training program.

The following recommendations address general safety and health issues:

\section{Recommendation \#5: Limit the number of consecutive shifts a fire fighter can work.}

Discussion: In 2004, NIOSH reviewed the research literature on the health effects of overtime and extended work shifts (typically 12-hour shifts compared to 8-hour shifts) [NIOSH 2004]. Overtime was associated with poorer perceived general health, increased injury rates, more illnesses, or increased mortality in 16 of 22 studies reviewed [NIOSH 2004]. Extended work shifts were associated with decreased alertness, increased fatigue, lower cognitive function, declines in vigilance, and increased injuries [NIOSH 2004]. Studies among physicians who worked very long shifts (>24 hours) reported deteriorating cognitive performance, more frequent patient errors, and more frequent motor vehicle accidents after their shift [NIOSH 2004; Barger et al. 2005; Barger et al. 2006].

Currently, the FD works 48 hours followed by 96 hours off. However, fire fighters are allowed to 
exchange shifts, thereby setting up the possibility that a fire fighter may be on duty for up to 72 hours. While FD fire fighters frequently get some sleep during their work shifts, this sleep can be interrupted by the numerous ambulance calls that are made during the night and early morning hours. Although there are no data linking chronic sleep deprivation with sudden cardiac death, chronic sleep deprivation could result in a decline in cognitive function, possibly impairing judgment during incident command or fire suppression. Allowing fire fighters to work consecutive shifts may represent not only an injury and illness risk for individual fire fighters, but also a safety and health risk for their coworkers and the public.

\section{Recommendation \#6: Discontinue routine screening chest $x$-rays for members, unless clinically indicated.}

Discussion: The fire department obtains chest x-rays during the pre-employment/pre-placement medical evaluation and routinely every 5 years (more frequently for HAZMAT and urban search and rescue teams). NFPA 1582 recommends an initial baseline chest x-ray and repeat chest x-rays every 5 years or as medically indicated [NFPA 20013a]. Requiring chest x-rays prior to 5 years exposes members to unnecessary radiation and is an unnecessary expense for the fire department [Tigges et al. 2004]. Routine screening chest x-rays are not recommended by the OSHA hazardous waste operations and emergency response standard, unless clinically indicated (e.g., respiratory symptoms) [NIOSH 1985; CFR 2012].

\section{References}

ACE [2015]. American Council on Exercise.

[http://www.acefitness.org/acefit/healthy_living_tools_content.aspx?id=2]. Date accessed: March 2015.

AHA [2014]. Understand your risk for arrhythmia? Dallas, TX: American Heart Association. [http://www.heart.org/HEARTORG/Conditions/Arrhythmia/UnderstandYourRiskforArrhythmia/Unde rstand-Your-Risk-for-Arrhythmia_UCM_002024_Article.jsp]. Date accessed: March 2015.

AHA (American Heart Association) [2015]. Understand your risk of heart attack. Dallas, TX: American Heart Association. [http://www.heart.org/HEARTORG/Conditions/HeartAttack/UnderstandYourRiskofHeartAttack/Unde rstand-Your-Risk-of-Heart-Attack_UCM_002040_Article.jsp]. Date accessed: March 2015.

Aldana SG [2001]. Financial impact of health promotion programs: a comprehensive review of the literature. Am J Health Promot 15(5):296-320.

Baltazar RF [2009]. Basic and bedside electrocardiography. Baltimore, MD: Lippincott, Williams, and Wilkins, p. 135.

Barger L, Cade B, Ayas, Cronin J, Rosner B, Speizer F, Czeisler C; Harvard Work Hours, Health, and Safety Group [2005]. Extended work shifts and the risk of motor vehicle crashes among interns. N Engl J Med 352:125-34.

Barger L, Ayas N, Cade B, Cronin J, Rosner B, Speizer F, Czeisler C [2006]. Impact of extendedduration shifts on medical errors, adverse events, and attentional failures. PLoS Med 
3:e487. [http://www.plosmedicine.org/article/info:doi/10.1371/journal.pmed.0030487]. Date accessed: March 2015.

Blevins JS, Bounds R, Armstrong E, Coast JR [2006]. Health and fitness programming for fire fighters: does it produce results? Med Sci Sports Exerc 38(5):S454.

Bonow RO, Carabello BA, Chatterjee K, de Leon AC Jr., Faxon DP, Freed MD, Gaasch WH, Whitney Lytle B, Nishimura RA, O'Gara PT, O’Rourke RA, Otto CM, Shah PM [2006]. ACC/AHA 2006 guidelines for the management of patients with valvular heart disease: executive summary. A report of the American College of Cardiology/American Heart Association Task Force on Practice Guidelines (Writing Committee to Revise the 1998 Guidelines for the Management of Patients With Valvular Heart Disease). J Am Coll Card 48(3):e1-e148.

CDC (Centers for Disease Control and Prevention) [2014]. BMI - Body Mass Index. [http://www.cdc.gov/healthyweight/assessing/bmi/index]. Date accessed: March 2015.

CFR [2012]. Code of Federal Regulations [29 CFR 1910.120]. OSHA standards interpretation. Medical surveillance requirements for hazmat workers. Washington, DC: U.S. Government Printing Office, Office of the Federal Register.

[http://www.osha.gov/pls/oshaweb/owadisp.show_document?p_table=INTERPRETATIONS\&p_id=2 8301]. Date accessed: March 2015.

Dempsey WL, Stevens SR, Snell CR [2002]. Changes in physical performance and medical measures following a mandatory firefighter wellness program. Med Sci Sports Exerc 34(5):S258.

Gabbay U, Yosefy C [2010]. The underlying causes of chordae tendinae rupture: a systematic review. Int J Cardiol 143(2):113-118.

[http://www.sciencedirect.com/science?_ob=ArticleURL\&_udi=B6T16-4YJCTHG-1\&_user = 925725\&_coverDate $=08 \% 2 F 20 \% 2 F 2010 \&$ alid=1449042464\&_rdoc=1\&_fmt=high\&_orig=sea

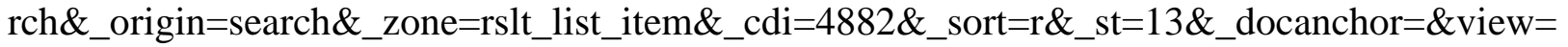
c\&_ct=1\&_acct=C000046148\&_version=1\&_urlVersion=0\&_userid=925725\&md5=9493986b7 a74eebd58eb3feaac62a8b0\&searchtype=a]. Date accessed: March 2015.

Gerkin R, Kelley P, Perry R [1997]. Correlation of VO2max during maximal treadmill stress testing with $\mathrm{VO} 2$ at $85 \%$ predicted maximal heart rate: A retrospective review of the Phoenix fire department treadmill protocol. Technical report to the medical director of the Phoenix Fire Department Medical Center.

Gibbons RJ, Balady GJ, Bricker JT, Chaitman BR, Fletcher GF, Froelicher VF, Mark DB, McCallister BD, Mooss AN, O'Reilly MG, Winters WL Jr., Antman EM, Alpert JS, Faxon DP, Fuster V, Gregoratos G, Hiratzka LF, Jacobs AK, Russell RO, Smith SC Jr. [2002]. ACC/AHA 2002 guideline update for exercise testing: a report of the American College of Cardiology/American Heart Association Task Force on Practice Guidelines. Circulation 106(14):1883-1892.

IAFF, IAFC [2008]. The fire service joint labor management wellness/fitness initiative. 3rd ed. Washington, DC: International Association of Fire Fighters, International Association of Fire Chiefs. 
Kuehl KS, Elliot DL, Goldberg L, Moe EL, Perrier E, Smith J [2013]. Economic benefit of the PHLAME wellness programme on firefighter injury. Occup Med 63(3):203-209.

Levy D, Garrison RJ, Savage DD, Kannel WB, Castelli WP [1990]. Prognostic implications of echocardiographically determined left ventricular mass in the Framingham Heart Study. N Engl J Med 323(24):1706-1707.

Libby P [2013]. Mechanisms of acute coronary syndromes and their implications for therapy. N Engl J Med 368(21):2004-2013.

Malkowski MJ, Pearson AC [2000]. The echocardiographic assessment of the floppy mitral valve: an integrated approach. In: Boudoulas J, Wooley CF (eds). Mitral valve: floppy mitral valve, mitral valve prolapse, mitral valvular regurgitation. $2^{\text {nd }}$ ed. Armonk, NY: Futura, pp. 231-252.

Mayo Clinic [2015]. Heart arrhythmias. [http://www.mayoclinic.com/health/heartarrhythmias/DS00290/METHOD=print\&DSECTION=all]. Date accessed: March 2015.

Meyerburg RJ, Castellanos A [2008]. Cardiovascular collapse, cardiac arrest, and sudden cardiac death. In: Fauci AS, Braunwald E, Kasper DL, Hauser SL, Longo DL, Jameson JL, Loscalzo J, eds. Harrison's principles of internal medicine. 17th ed. New York: McGraw-Hill, pp. 1707-1713.

Mier CM, Gibson AL [2004]. Evaluation of a treadmill test for predicting the aerobic capacity of firefighters. Occup Med (Lond). 54(6):373-378. Epub 2004 Sep 3.

Mirvis DM, Goldberger AL [2012]. Electrocardiography. In: Bonow RO, Mann DL, Zipes DP, Libby P, eds. Braunwald's heart disease. 9th ed. Philadelphia: Elsevier Saunders, p. 146.

NFPA [2008]. Standard on health-related fitness programs for fire fighters. Quincy, MA: National Fire Protection Association. NFPA 1583.

NFPA [2013a]. Standard on comprehensive occupational medical program for fire departments. Quincy, MA: National Fire Protection Association. NFPA 1582.

NFPA [2013b]. Standard on fire department occupational safety and health program. Quincy, MA: National Fire Protection Association. NFPA 1500.

NHLBI [2014]. Who is at risk for coronary artery disease? National Heart, Lung, and Blood Institute. [http://www.nhlbi.nih.gov/health/health-topics/topics/cad/atrisk.html]. Date accessed: March 2015.

NIOSH [1985]. Occupational safety and health guidance manual for hazardous waste site activities. Cincinnati, OH: U.S. Department of Health and Human Services, Public Health Service, Centers for Disease Control, National Institute for Occupational Safety and Health, DHHS (NIOSH) Publication No. 85-115. [http://www.cdc.gov/niosh/pdfs/85-115-a.pdf]. Date accessed: March 2015.

NIOSH [2004]. overtime and extended work shifts: recent findings on illnesses, injuries, and health behaviors. Cincinnati, OH: U.S. Department of Health and Human Services, Public Health Service, 
Centers for Disease Control and Prevention, National Institute for Occupational Safety and Health. [http://www.cdc.gov/niosh/docs/2004-143/]. Date accessed: March 2015.

Neumar RW, Otto CW, Link MS, Kronick SL, Shuster M, Callaway CW, Kudenchuk PJ, Ornato JP, McNally B, Silvers SM, Passman RS, White RD, Hess EP, Tang W, Davis D, Sinz E, Morrison LJ [2010]. Part 8: Adult advanced cardiovascular life support. 2010 American Heart Association Guidelines for cardiopulmonary resuscitation and emergency cardiovascular care. Dallas, TX: American Heart Association.

O'Gara P, Braunwald E [2008]. Valvular heart disease. In: Fauci AS, Braunwald E, Kasper DL, Hauser SL, Longo DL, Jameson JL, Loscalzo J, eds. Harrison's principles of internal medicine. 17th ed. New York: McGraw-Hill, pp. 1465-1480.

Schneider EL [2010]. Firefighter fitness: a health and wellness guide. New York: Nova Science Publishers.

Siegel RJ [1997]. Myocardial hypertrophy. In: Bloom S, ed. Diagnostic criteria for cardiovascular pathology acquired diseases. Philadelphia, PA: Lippencott-Raven, pp. 55-57.

Stein AD, Shakour SK, Zuidema RA [2000]. Financial incentives, participation in employer sponsored health promotion, and changes in employee health and productivity: HealthPlus health quotient program. J Occup Environ Med 42(12):1148-1155.

Tierney MT, Lenar D, Stanforth PR, Craig JN, Farrar RP [2010]. Prediction of aerobic capacity in firefighters using submaximal treadmill and stairmill protocols. J Strength Cond Res 24(3):757-764.

Tigges S, Roberts DL, Vydareny KH, Schulman DA [2004]. Routine chest radiography in a primary care setting. Radiol 233(2):575-578.

Womack JW, Humbarger CD, Green JS, Crouse SF [2005]. Coronary artery disease risk factors in firefighters: effectiveness of a one-year voluntary health and wellness program. Med Sci Sports Exerc 37(5):S385.

\section{Investigator Information}

This incident was investigated by the NIOSH Fire Fighter Fatality Investigation and Prevention Program, Cardiovascular Disease Component in Cincinnati, Ohio. Mr. Tommy Baldwin (MS) led the investigation and co-authored the report. Mr. Baldwin is a Safety and Occupational Health Specialist, a National Association of Fire Investigators (NAFI) Certified Fire and Explosion Investigator, an International Fire Service Accreditation Congress (IFSAC) Certified Fire Officer I, and a former Fire Chief and Emergency Medical Technician. Dr. Thomas Hales (MD, MPH) provided medical consultation and co-authored the report. Dr. Hales is a member of the NFPA Technical Committee on Occupational Safety and Health, and Vice-Chair of the Public Safety Medicine Section of the American College of Occupational and Environmental Medicine (ACOEM).

\section{Disclaimer}

Mention of any company or product does not constitute endorsement by the National Institute for Occupational Safety and Health (NIOSH). In addition, citations to Web sites external to NIOSH do not 
constitute NIOSH endorsement of the sponsoring organizations or their programs or products. Furthermore, NIOSH is not responsible for the content of these Web sites. 


\section{Appendix A Autopsy Findings}

- Coronary arteries were examined but no significant atherosclerosis was found

- Hypertensive heart disease

- Cardiomegaly (enlarged heart; heart weighed 600 grams [g]; predicted normal weight is $391 \mathrm{~g}$ [ranges between $296 \mathrm{~g}$ and $516 \mathrm{~g}$ as a function of sex, age, and body weight]) [Silver and Silver 2001]

○ Concentric left ventricular hypertrophy

- Left ventricle and interventricular septum thickened (1.7 centimeter [cm] each $\circ \quad$ Normal at autopsy is $0.76-0.88 \mathrm{~cm}$ [Colucci and Braunwald 1997]

- Normal by echocardiographic measurement is $0.6-1.0 \mathrm{~cm}$ [Connolly and Oh 2012]

- Mild atherosclerotic change in main systemic vessels

- Moderate mitral valve prolapse

- No evidence of acute coronary artery thrombosis (blood clot in the coronary arteries)

- No evidence of a pulmonary embolus (blood clot in the lung arteries)

- Toxicology results were not available to the NIOSH investigator

\section{REFERENCES}

Colucci WS, Braunwald E [1997]. Pathophysiology of heart failure. In: Braunwald, ed. Heart disease. 5th ed. Philadelphia, PA: W.B. Saunders Company, p. 401.

Connolly HM, Oh JK [2012]. Echocardiography. In: Bonow RO, Mann DL, Zipes DP, Libby P, Braunwald E, eds. Heart disease: a text of cardiovascular medicine. 9th ed. Vol. 1. Philadelphia, PA: Elsevier Saunders, p. 216.

Silver MM, Silver MD [2001]. Examination of the heart and of cardiovascular specimens in surgical pathology. In: Silver MD, Gotlieb AI, Schoen FJ, eds. Cardiovascular pathology. 3rd ed. Philadelphia, PA: Churchill Livingstone, pp. 8-9. 


\section{Appendix B \\ Classification of Mitral Valve Prolapse [Bonow et al. 1998]}

Primary MVP

Familial

Nonfamilial

Marfan's syndrome

Other connective tissue diseases

Secondary MVP

CAD

Rheumatic heart disease

Reduced LV dimensions

Hypertrophic cardiomyopathy

Atrial septal defect

Pulmonary hypertension

Anorexia nervosa

Dehydration

Straight-back syndrome/pectus excavatum

"Flail" mitral valve leaflet(s)

Normal variant

Inaccurate auscultation

"Echocardiographic heart disease" 